\title{
QUALIFICATION OF A CASTING TECHNOLOGY FOR PRODUCTION OF TITANIUM ALUMINIDE COMPONENTS FOR AERO-ENGINE APPLICATIONS
}

\author{
Julio Aguilar ${ }^{\mathrm{a}}$, Andre Schievenbusch ${ }^{\mathrm{b}}$ and Oliver Kättlitz ${ }^{\mathrm{c}}$ \\ Access e.V., Intzestr. 5, D-52072 Aachen, Germany \\ aj.aguilar@access-techcenter.de, ${ }^{b}$ a.schievenbusch@access-technology.de, \\ co.kaettlitz@access-techcenter.de
}

Keywords: Titanium, Titanium Aluminides, TiAl, Investment Casting, Casting, Aerospace, Intermetallics

\begin{abstract}
Actual alloy and process development for high temperature turbine applications in the aerospace sector is strongly aimed at reaching the high demands on reduction of $\mathrm{CO} 2$ emissions responsible for the green house effect. Based on weight reduction the main objective resides in improving engine performance and efficiency. Last generation intermetallic titanium aluminides $(\gamma-\mathrm{TiAl})$ have a big potential to reach this goals. $\gamma$-TiAl is nevertheless a very demanding material requiring very sophisticated processing routes. Access has developed a casting route for production of high quality $\gamma$-TiAl components based on skull induction melting (SIM) and centrifugal investment casting. Although the feasibility of the technology has been already proven in earlier projects, it is still necessary to improve the process for series production of parts with the high quality standards required by the aerospace industry. With aid of a new developed centrifugal casting facility Access and its partners are conducting a comprehensive qualification process for the production of aerospace components, e.g. low pressure turbine blades. Basic issues comprising casting cluster design based on numerical simulation, process control and quality management are being addressed.
\end{abstract}

\section{Introduction}

Actual alloy developments for high temperature applications in the aerospace industry are mainly aimed on reducing $\mathrm{CO} 2$ emissions by means of weight reduction and improvement of high temperature capabilities of engine components. Last generation titanium-aluminides (TiAl) have a proven potential to reach this goal. Nevertheless TiAl is also a very demanding material for which special processing technologies have to be developed. Access has being developing and qualifying in pilot scale a complete production route for high quality TiAl components based on centrifugal investment casting.

Single phase $\gamma$-(TiAl) intermetallics exist in binary TiAl alloys with more than 48 at.- $\% \mathrm{Al}$ and provide very low solubility for interstitial impurities [1]. For this reason relative small traces of $\mathrm{H}$, $\mathrm{C}, \mathrm{N}$ and $\mathrm{O}$ lead to dramatic embrittlement. Further on, ductility and toughness can only be partially incremented by alloy modifications. Through the later development of two phase $\gamma$-(TiAl) alloys it was possible to improve both properties considerably [2]. Actual engineering alloys contain besides the main $\gamma$-(TiAl) phase small quantities of $\alpha_{2}\left(\mathrm{Ti}_{3} \mathrm{Al}\right) . \alpha_{2}\left(\mathrm{Ti}_{3} \mathrm{Al}\right)$ is more brittle and hard than $\gamma$ (TiAl) but has a higher solubility for interstitial impurities, thus reducing the amount of impurities within $\gamma$-(TiAl). Figure 1 shows an actualized Ti-Al phase diagram. Some changes were added specially at $\mathrm{Al}$ concentrations above 40 at.- $\%$. Modern casting alloys contain 44 to 49 at.- $\% \mathrm{Al}$ and have been relatively good evaluated in different research projects [3]. 


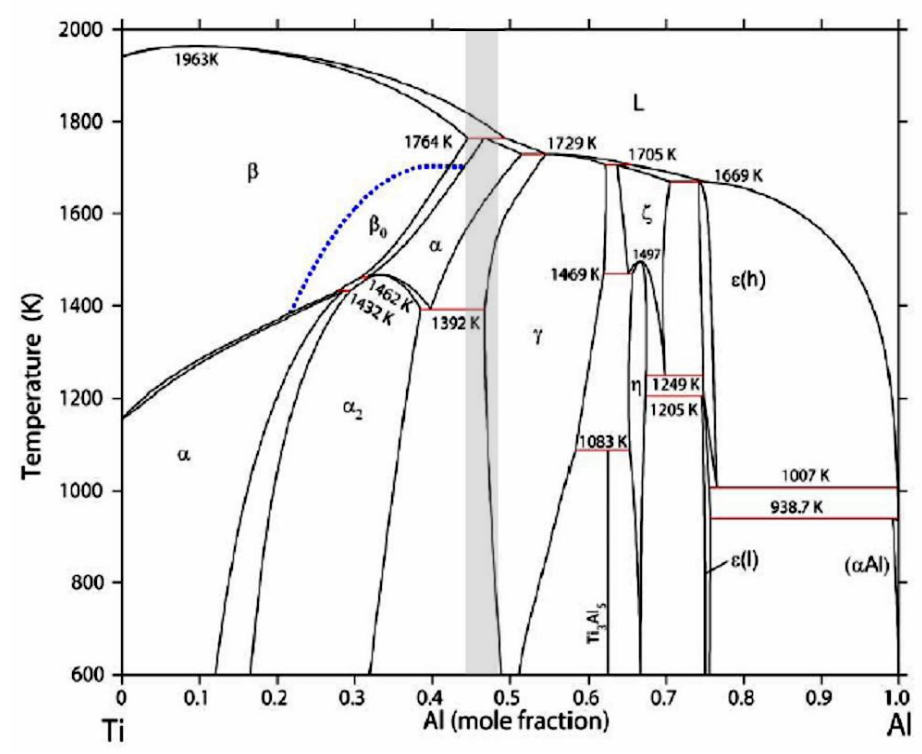

Figure 1: Modified TiAl phase diagram from Witusiewicz et al. (2008) [2]

\section{Alloying elements}

To increase high temperature properties and ductility at room temperature further alloying elements besides $\mathrm{Ti}$ and $\mathrm{Al}$ for formation of intermetallic phases are usually added. Although the effect mechanism of some of them is still not completely understood the alloying elements are usually divided in 3 classes for the most common alloys as shown in equation 1 [4]. It is important to remark, that the effect of some alloying elements can be drastically changed by the addition of further elements.

$$
\mathrm{Ti}-(45-49) \mathrm{Al}-(0-4) \mathrm{Cr}, \mathrm{Mn}, \mathrm{V}-(0,5-10) \mathrm{Nb}, \mathrm{W}, \mathrm{Mo}, \mathrm{Ta}-(0-1) \mathrm{B}, \mathrm{C}, \mathrm{Si} \quad[1]
$$

\section{TiAl casting alloys}

The first objectives during early developing of TiAl intermetallic alloys were centred in optimizing the alloy strength from RT up to $750^{\circ} \mathrm{C}$ and ductility at RT by Chromium and Manganese additions. So called $2^{\text {nd }}$ generation alloys posses wider process windows, better corrosion resistance and creep properties which allow their application beyond $760^{\circ} \mathrm{C}$. These qualities were already attractive enough to introduce them for industrial applications and first attemps to improve casting properties were conducted. Besides detailed analysis of annealing processes to induce grain refinement, the so called XD process was developed. By XD a complicated melt treatment with $\mathrm{TiB}_{2}$ is applied to obtain a fine lamellar microstructure in the as-cast condition.

The addition of high Niobium contents on alloys of the $3^{\text {rd }}$ generation resulted in acceptable RT ductility which allows for easier machining of cast components. Further more small additions of Boron resulted in a finely grained fine lamellar microstructure (FL) allowing direct use of as-cast components without the need of heat treatment [4].

\section{Melting TiAl}

TiAl melts are highly reactive and have to be processed under vacuum or Argon atmospheres using inert crucible materials. Special care has to be taken to prevent Al boiling while melting and superheating under vacuum. Under Argon the casting system must allow for venting to eliminate porosities caused by gas entrapment. A sophisticated melting technology is necessary to reduce Oxygen and Nitrogen pick-up down to levels that do not affect RT ductility. As shown in figure 2 strength and ductility change strongly as soon as $\mathrm{O}$ or $\mathrm{N}$ pick-up in ppm range occurs [5]. 
Besides the complex ,induction skull melting“ (ISM) in water cooled copper crucibles, the use of special ceramic crucibles with an Yttria coating system has been proven to be an alternative. Induction melting in ceramic crucibles enables higher melt superheating and better control of casting temperature by much lower furnace power, although some limited Oxygen pick-up has to be taken into account [6].
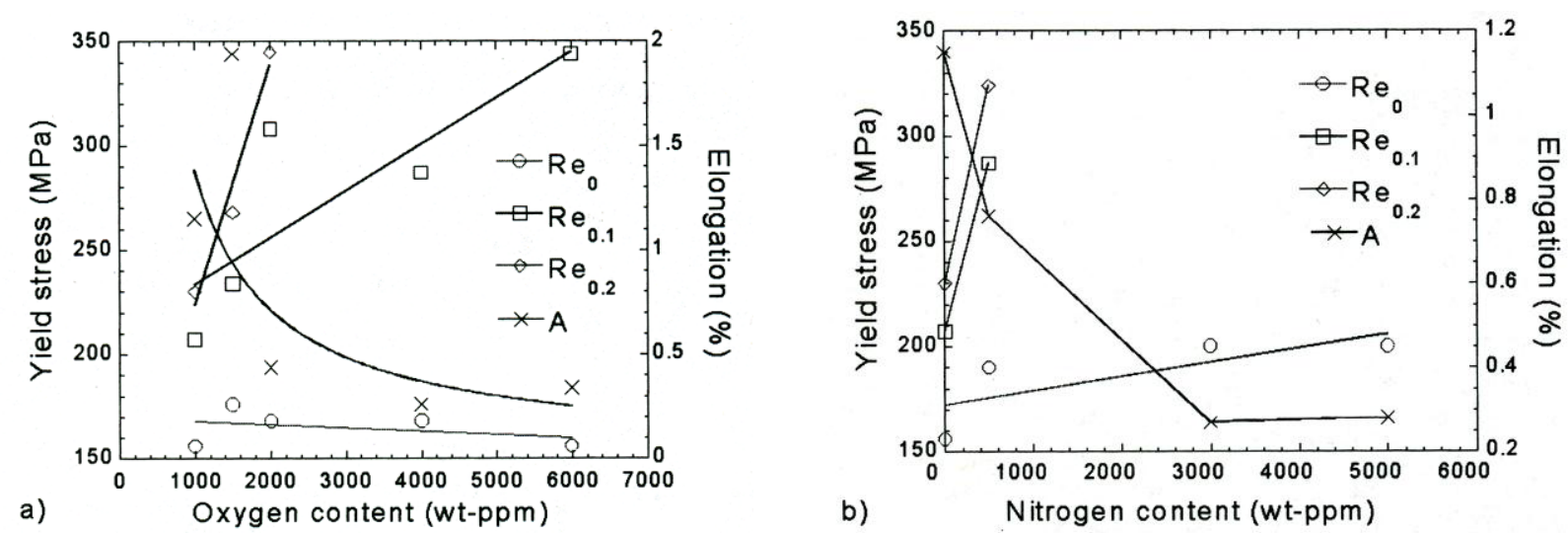

Figure 2: Influence of Oxygen (a) and Nitrogen (b) on yield strength and ductility of FL microstructures at RT. Nitrogen values are valid for constant Oxygen content of $1000 \mathrm{ppm}$. [6].

\section{Investment casting of TiAl}

Most TiAl cast parts are produced in investment casting. Some reasons for this are e.g. high temperature brittle-ductile transition, narrow solidification range, reactivity of solidifying melt with mould materials and cost and time intensive machining. The main steps of the process as described for qualifying the process for production of TiAl components are shown in figure 3.

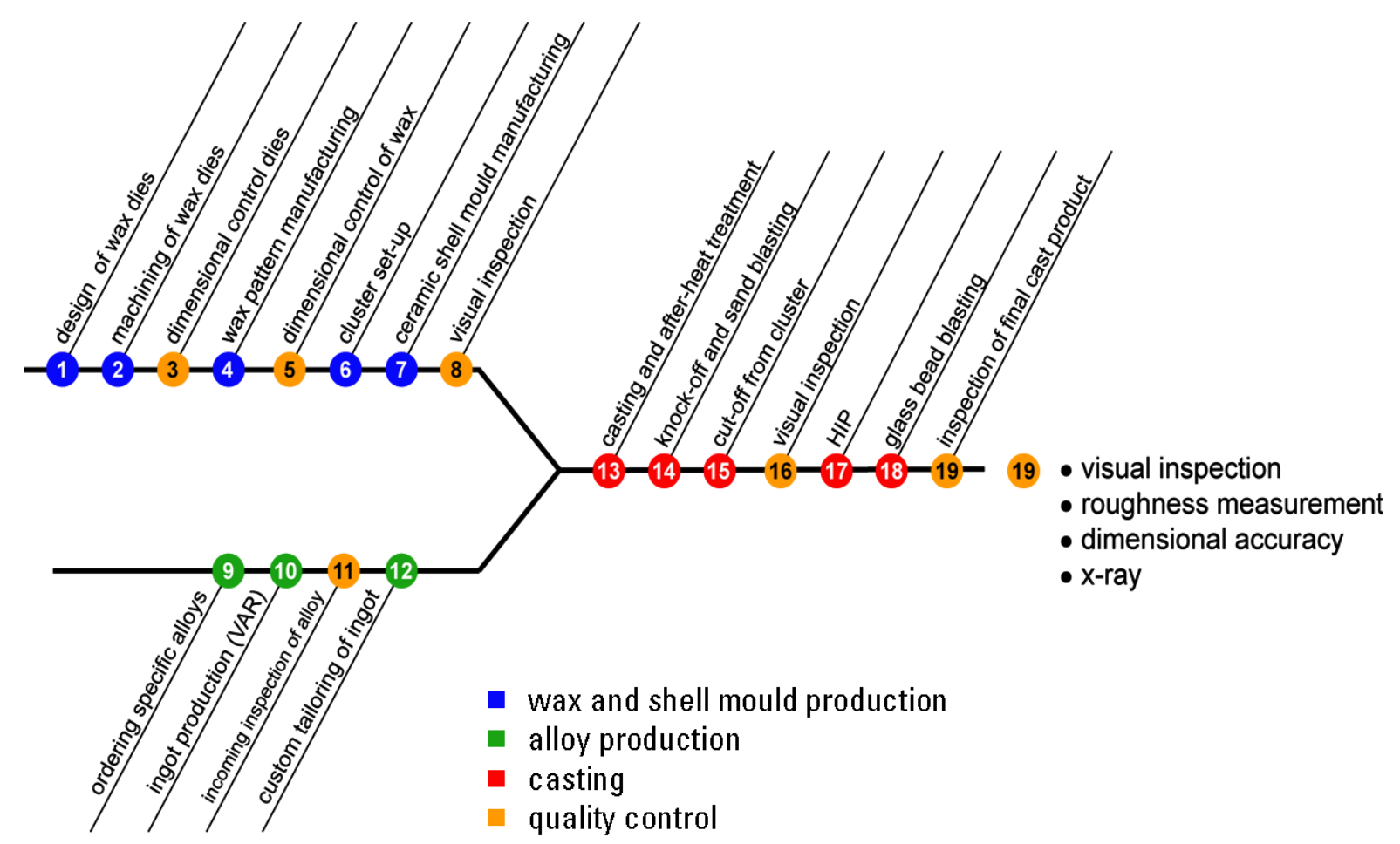

Figure 3: Process steps of investment casting process as developed for qualifying a process route for TiAl components.

\section{Process Qualification}

As exposed TiAl is a very demanding material which requires specially developed technologies for its processing. The qualification begins with the casting design based on CAD drawings of the finished part. The first aspect to be taken into account is shrinkage during processing. Shrinkage can 
be divided in three steps during the process: Wax shrinkage during production of patterns, ceramic shrinkage during firing of mould shells and metal shrinkage during casting. Further more shrinkage can locally vary depending on position in the die or mould. Once total shrinkage is calculated the dimensions of the CAD drawing are modified to compensate it and machined surfaces and interfaces for joining the part with gating system are provided. Based on CAD wax injection dies are manufactured. Besides dimensional accuracy special care has to be taken on surface quality. Any die surface defect or roughness will be reproduced down to the finished part. To prevent wear or distortion of die surface steel dies are preferred for aerospace applications. After checking on die quality the wax injection has to be qualified. Wax injection took place in a Modtech C35 machine with precise pressure and temperature controlling in order to reach a high level of reproducibility. After testing trials a set of parameters was frozen and working instructions were elaborated, so that further production always takes place under same conditions. Out of each production batch a certain number of patterns are randomly picked for testing dimensional accuracy. At this stage all wax patterns are numbered and documented for total process tracking.

Next step is designing of cluster set-up. A comprehensive combination of numerical simulation and casting trials leads to an optimized set-up. The optimized cluster set-ups are documented and frozen for further processing. After construction of special dies for wax injection of gating channels the cluster is manually assembled. After quality inspection each cluster becomes a production number for documentation and tracking.
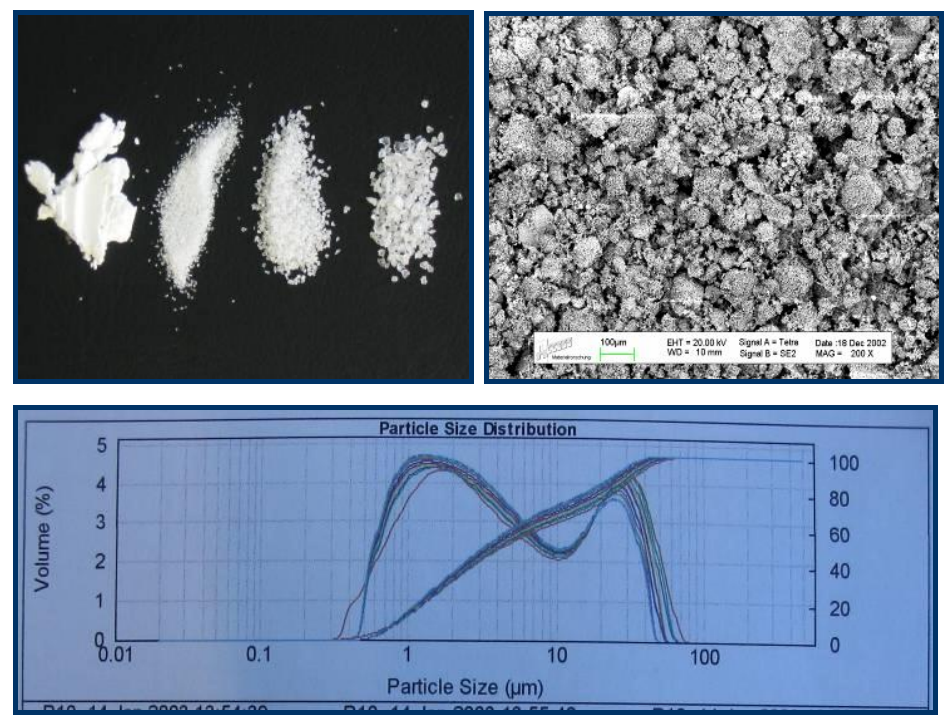

Figure 4: Control of incoming ceramic materials include grain size and distribution, chemical purity and grain geometry.
Following step is production of ceramic shell moulds. It is maybe the most demanding and complex of all process steps. Ceramic shell moulds are produced by covering the wax clusters with ceramic materials. This is achieved by dipping the cluster in ceramic slurry followed by sanding. The ceramic slurry provides a smooth surface while sand gives strength to the shell. This process is repeated several times between drying intervals until a defined shell thickness is achieved. Because of demands on surface quality and reactivity of TiAl melts against most oxide ceramics it is necessary to use Yttria for the front layers of the mould. For the back-up layers other ceramics may be applied. Very tight quality control of raw materials (purity, grain size, grain distribution and grain geometry) and slurries (liquid content, viscosity, $\mathrm{pH}$ and binder content) has to be applied to maintain quality and for process stability. Further more time, room humidity and temperature have to be strictly constant. Once ceramic shell mould thickness is reached the moulds are brought to an autoclave for dewaxing. To avoid damaging of front layers or cracking steam temperature and pressure as well as process times are continuously controlled and documented. Next step on shell mould manufacturing is firing. Because of Yttria front layers this has to be realized at temperature above $1350^{\circ} \mathrm{C}$ with very good control of heating, dwelling and cooling times. After firing all shell moulds are washed to eliminate loose residues, inspected and released for further processing. Defective moulds are also documented to keep track of possible problems in the process. Prior to casting the mould are insulated with a special fibre free material. 
Parallel to shell mould manufacturing the preparation an approval of casting alloy is conducted. In case of TiAl the alloy is obtained together with quality certificate as VAR (vacuum-arc-remelting) Ingots from the supplier. Typical tolerance for alloying elements is $\pm 0,7$ at. $\%$ with a maximum oxygen content of 600 wt.-ppm. Using water jet to prevent contaminations the ingot is cut into pellets for melting and casting.

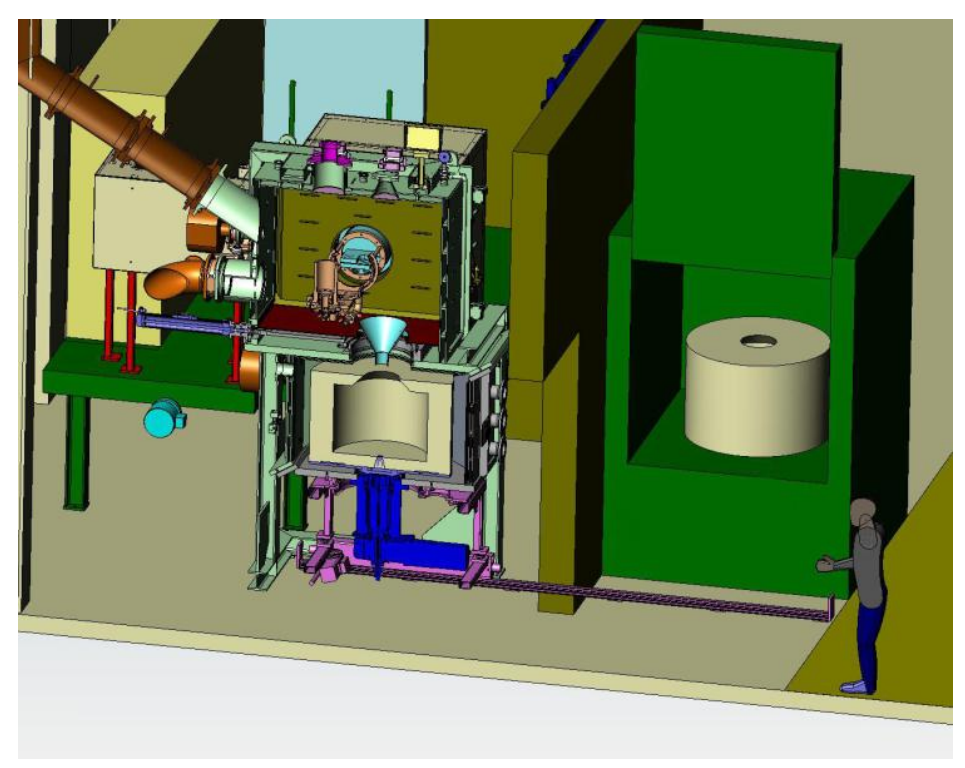

Figure 5: Leicomelt 5TP Centrifugal casting concept. Melting capacity: $8.0 \mathrm{~kg}$; Superheat: $\Delta \mathrm{T} \approx 20$ to $60 \mathrm{~K}$; Process duration: 20 min; Very low oxygen pick-up; up to 350 RPM

be strictly controlled to prevent corrosion, deformation or microstructure modifications.

In order to qualify the process with regard to part quality and reproducibility quality assurance specifications (QS) have to be developed and implemented. This represents quite a challenge since TiAl is still not a wide spread material for series production. Quality specifications for dimensional accuracy, visual inspection, internal defects, crack detection and roughness were developed.

\section{Conclusions}

Investment casting of TiAl components is a long and complex process requiring very close control and strict documentation in order to achieve the required qualification for production of castings. Not only quality but also reproducibility and robustness are key aspects for success. Access and its project partners have been already able to qualify this production technology for low pressure turbine blades (LPTB). Besides process development, quality assurance and documentation several thousand parts with standardized quality have to be delivered to demonstrate process reproducibility and robustness.
Casting of shell moulds takes place in a centrifugal casting device from ALD. A 6. Melting is done in ISM under vacuum. Very low oxygen pick-up is expected during melting and super-heating. Most important casting parameters are superheating of alloy, shell mould temperature, rotation speed for fast mould filling and high casting pressure, adequate shell mould positioning to make use of centrifugal and coriolis forces and cooling curves.

Following processing includes knock-off of ceramic shell, cutting and polishing of castings. Knock-off and polishing are usually done by sand blasting and cutting using high pressure water jet. In case of aerospace applications high temperature isostatic pressing (HIP) is used to close rest porosities. HIP parameters have to 


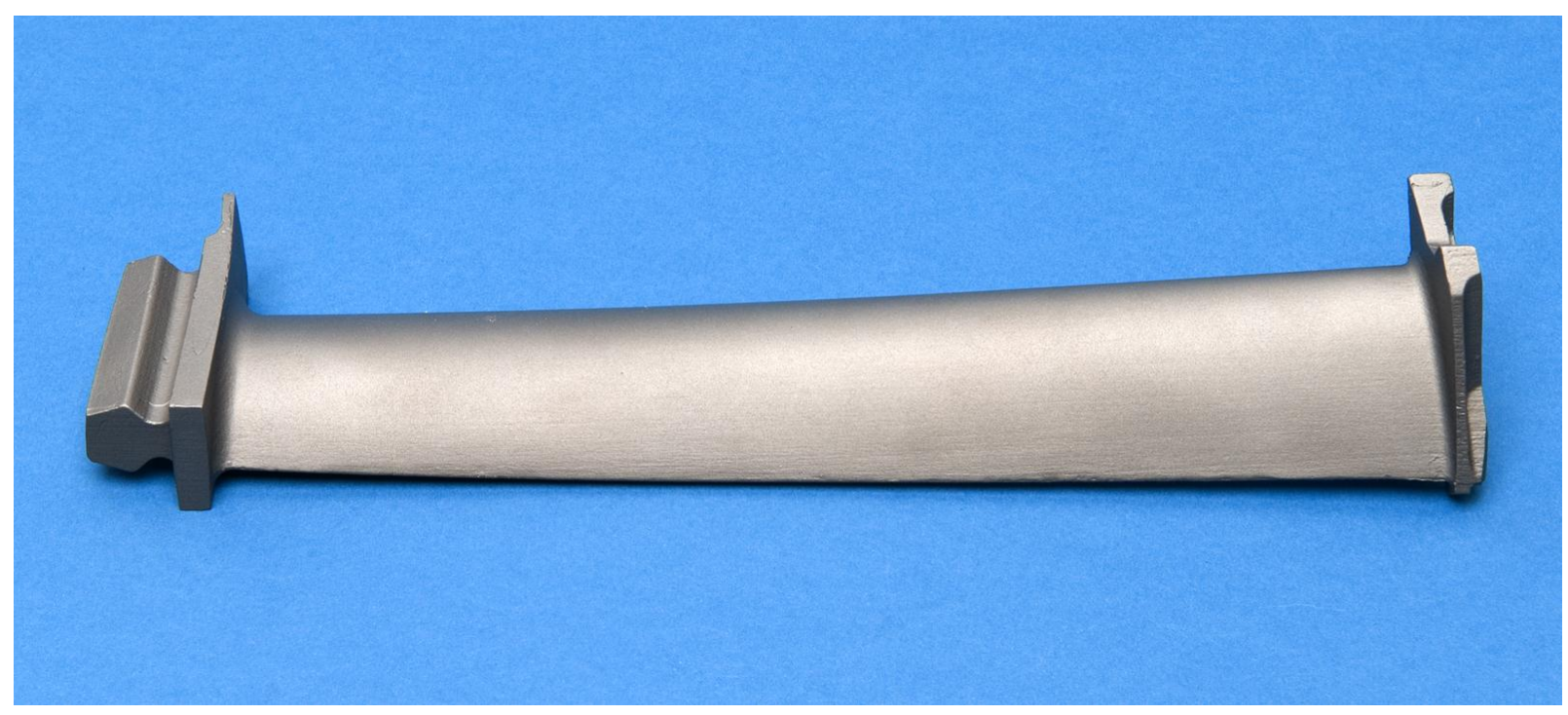

Figure 6: TiAl low pressure turbine blade ready for delivery

\section{Literatur}

[1] H. Kestler, H. Clemens, „Herstellung, Verarbeitung und Anwendung von Đo(TiAl)Basislegierungen“, In: M. Peters, C. Leyens, Titan und Titanlegierungen, WILEY-VCH Verlag, 2002, Seite 269-396

[2] Witusiewicz, V.T. , A.A. Bondar, U. Hecht, S. Rex und T.Ya. Velikanova: The Al-B-Nb-Ti system III. Thermodynamic re-evaluation of the constituent binary system Al-Ti. Journal of Alloys and Compounds, 465, 64-77, 2008

[3] J. C. Schuster, M. Palm, "Reassessment of the Binary Aluminium-Titanium Phase Diagram" Journal of Phase Equilibria and Diffusion, 27 (2006), pages 255-277

[4] Y. W. Kim (1994): “Ordered Intermetallic Alloys, Part III: Gamma Titanium Aluminides”, JOM, 46 (7), Pages 30-39

[5] D. Bala Wortberg, "Feinguss von Turbinenrädern aus TiAl", Promotion, TU HamburgHarburg, 2003

[6] J. Schädlich-Stubenrauch, „Entwicklung einer Schleuderfeingiesstechnologie für kleine, dünnwandige und filigrane Gussteile aus Titan und Titanlegierungen“, Promotion, GießereiInstitut RWTH Aachen, 1989 